\title{
A COMPREHENSIVE STUDY ON LITERATURE EVIDENCE, CLINICAL STUDIES AND PRACTICES OF HERBAL DRUGS FOR DIABETIC NEUROPATHY AND CARDIOMYOPATHY
}

\author{
ARSHIYA SHAMIM, HEFAZAT H SIDDIQUI, TARIQUE MAHMOOD*, PARAMDEEP BAGGA, RANJAN KUMAR
}

Department of Pharmacy, Integral University, Lucknow, Uttar Pradesh, India. Email: ansaritariq79@yahoo.co.in

Received: 30 March 2017, Revised and Accepted: 06 June 2017

\begin{abstract}
Diabetes mellitus is a worldwide epidemic disease that eventually advances to a chronic stage and affects different vital organs by intensifying the underlying pathological factors, and through the remodeling of the tissues by the generation of reactive oxygen species leading to the development of respective organ failure. Two such complications are painful neuropathy and cardiomyopathy; both of which are common and progressive complications of diabetes. The symptoms of peripheral neuropathy include tingling, burning, lancinating pain, hyperesthesia, and allodynia. The course of the disease progression may vary from intermittent, mild symptoms to severe chronic, and daily pain; which culminates into poor quality of life. Another complication of diabetes mellitus, diabetic cardiomyopathy, is defined as a ventricular dysfunction disorder that occurs in diabetic patients. The development of the disease is characterized by a hidden subclinical period, during which cellular, structural changes and abnormalities lead to diastolic dysfunction, followed by systolic dysfunction, and terminating into heart failure. Left ventricular hypertrophy, metabolic abnormalities, extracellular matrix changes, small vessel disease, cardiac autonomic neuropathy, insulin resistance, oxidative stress, and apoptosis are the most important pathological advancements that lead to diabetic cardiomyopathy. Various pharmaceutical agents from different pharmacological categories have been proposed for the symptomatic treatment of painful diabetic neuropathy; however, it is a herculean task to select a drug due to the wide range of choices and lack of consistent guidelines for treatment. Similarly, treatment of cardiomyopathy is based on the general therapeutic rules of management of heart failure and no specifications have yet been addressed for this condition. Therefore, more studies are required to improve our knowledge of these complex syndromes. From this perspective, this review is designed to delineate a general overview of neuropathy and cardiomyopathy, referring to the conventional therapies in use and possible unconventional, natural, herbal, and safe treatments for both the abovementioned complications of diabetes.
\end{abstract}

Keywords: Cardiomyopathy, Diabetes, Herbal treatment, Neuropathy, Neuropathic pain, Oxidative stress, Ventricular hypertrophy.

(C) 2017 The Authors. Published by Innovare Academic Sciences Pvt Ltd. This is an open access article under the CC BY license (http://creativecommons. org/licenses/by/4. 0/) DOI: http://dx.doi.org/10.22159/ajpcr.2017.v10i9.18785

\section{INTRODUCTION}

Statistical insight to diabetes mellitus

Diabetes mellitus is one of the most common, increasing, and serious public health problems among all the metabolic disorders worldwide both for the disease itself and for associated severe secondary complications. As per data recorded and updated to March 2013, provided by the World Health Organization and also reported by one of the Lancet journals (Diabetes -a global threat; 2011), the statistical data related to diabetes mellitus are alarming, there has been an increased incidence of diabetes cases from 1980 to 2008 when number of patients increased from 153 million to 347 million people worldwide suffering with diabetes mellitus. Moreover, it is predicted that this amount will increase to 380 million in 2025, representing $7.1 \%$ of the world's adult population [1-4]. On the basis of investigations carried by Chang et al. 2013; Espelt et al. 2013; a total of 57 million deaths occurred in the World during 2008, of which 36 million (63\%) were due to noncommunicable diseases, among these, diabetes alone caused 1.3 million deaths. Therefore, it is projected as a global health problem. Today, over $90 \%$ of diabetic patients are diagnosed with type 2 diabetes mellitus (T2DM), with an increased incidence in recent years probably due to an increased prevalence of its main risk factors (obesity and sedentary life). Nephropathy, retinopathy, cardiomyopathy, and peripheral neuropathy are all recognized as important complications in about 50\% of diabetes mellitus patients, mostly with improper glycemic control or unsuccessful management of disease [5-10].

\section{DIABETIC PERIPHERAL NEUROPATHY}

The International Association for the Study of Pain defines neuropathic pain as "pain resulting from disease or damage of the peripheral or central nervous systems, and from dysfunction of the nervous system.
Neuropathic pain could be of many types such as paresthesias (numbness or tingling), dysesthesias (electric shock phenomenon), hyperesthesia (increased sensitivity to mild painful stimuli), hyperalgesia (increased sensitivity to normally painful stimuli), hyperpathia (pain produced by subthreshold stimuli), spontaneous pain, and allodynia (pain produced by normally non-painful stimuli. Diabetic peripheral neuropathy is characterized by symptoms such as pain, tingling, or numbness, loss of feeling in the hands, arms, feet, and legs. Painful neuropathy is common and in a few cases enfeebling complication of diabetes. The clinical trials conducted on patients suffering from type II diabetes (Davies et al. 2006; Ziegler et al. 2009) concluded that approximately one in four people with diabetes might be affected by chronic neuropathic pain. Patients often complain of symptoms such as discomfort, typically starting in the distal feet, but progressing proximally over time. Other symptoms such as numbness, tingling, burning, aching, electric shocks, or lancinating pain have also been observed, as stated in a review by Huizinga and Peltier, 2007. The body parts often affected include the legs, arms, hands, and fingers. The pain may be constant or intermittent, and there may be associated nocturnal worsening. Patients may also experience allodynia, when non-painful stimuli also become painful or hyperesthesia, when normally painful stimuli become excruciatingly painful [11-15].

\section{CURRENT TREATMENT APPROACHES FOR DIABETIC PERIPHERAL} NEUROPATHY

Although treatment of pain is critical to improvize the quality of life, it must be considered only one aspect of overall cure. Symptomatic management of neuropathy is altogether apart from treatment regimen for the disease itself, and therefore, aggressive treatment of underlying diabetes remains paramount as only then the patients can be completely 
cured. Control of blood pressure, lipids, and other microvascular risk factors are necessary for effective long-term management of diabetes. There are a few medications which have been vetted in large and randomized on the basis of placebo-controlled or head-to-head clinical trials. Interpretation of the available data can be challenging because variables such as dosing, duration of treatment, and the definition of successful treatment may vary among studies. As stated in a study conducted by Gore et al. 2008, certain recommendations of guidelines and consensus statements available often differ, and many medications have adverse effects or interactions with medications used to treat diabetes. There are older medications, such as tricyclic antidepressants, which are commonly used to treat painful diabetic neuropathy but have not been tested in randomized clinical trials for this condition. These older medications may be excluded from recommended guidelines which use strict criteria, given their potential efficacy and utility. Hence, a report by Van et al.; 2009, states that due to these limitations, the actual implementation of treatment for painful diabetic neuropathy may prove daunting to clinicians and likely contributes to patients remaining untreated or undertreated [16-19].

A group of medications are suggested for use as first-, second-, and third-line treatment for painful diabetic neuropathy. These clinical suggestions are based on the criteria including evidence of efficacy, safety, tolerability, drug interactions, and cost. The list of reviewed drugs is not claimed to be an encyclopedia of all agents used to treat painful diabetic neuropathy, but have been rather compiled keeping a practical perspective of treatment in mind with substantial available evidence. First-line medications are supported by evidence from three or more randomized clinical trials in patients with painful diabetic neuropathy, while second-line medications are supported by evidence from two randomized clinical trials in patients with this condition. Third-line medications are commonly used to treat painful diabetic neuropathy and are supported by evidence from two or more randomized clinical trials in patients with this condition but also have conflicting data reported. Third-line medications offer treatment options for patients who have either not tolerated or have been unable to take first- and second-line drugs [20-22].

\section{CLINICAL TRIALS ON DIABETIC PERIPHERAL NEUROPATHY [23-41] (TABLE 1)}

\section{Clinical case}

Various clinical cases on treatment and management of diabetic neuropathy have been reported by Hovaguimian and Gibbons; 2011, one such case is mentioned below as a reference.

This is a clinical case of a 59-year-old woman suffering from type 2 diabetes with complaints of numbness and pins for the past 2 years. Over the past 4 months, the symptoms have become increasingly bothersome. She has been treated in the past with gabapentin $300 \mathrm{mg}$. Her past medical history is remarkable for liver disease secondary to alcohol use with subsequent diabetes and thrombocytopenia. She has also had both hepatic encephalopathy and hepatorenal syndrome in the past. Her paresthesias have been persistent and may also be influencing her mood; therefore, symptomatic treatment may help improve her quality of life, and hence, the only first-line drugs without a contraindication in liver disease are pregabalin and gabapentin. As both gabapentin and pregabalin have similar mechanisms of action, it is, therefore, reasonable to repeat a trial of gabapentin first. The starting dose for gabapentin is $300 \mathrm{mg}$ daily, and this dose can be titrated as tolerated to symptomatic relief or to $1200 \mathrm{mg}$ thrice daily [42].

Diabetic cardiomyopathy is another complication of diabetes on which earliest data was reported four decades ago, hence, substantial information on its pathogenesis and clinical features had been accumulated. The relationship between diabetes mellitus and heart failure has been known for many years and includes several underlying pathogenesis. Leyden in 1881 first claimed that diabetic cardiomyopathy is a common complication of diabetes and one worthy of attention. In 1888, Mayer reported that diabetes is a metabolic disorder that can lead to heart disease. Finally, the term "diabetic cardiomyopathy" was coined by Rubler in 1972, after conducting post-mortem studies in diabetic patients with heart failure who had no medical history of alcoholism, hypertension, coronary disease, and other structural heart diseases. Prolonged diabetes increases fatty acid metabolism, inhibits glucose oxidation and modifies intracellular signaling in the heart, leading to impairments in multiple steps of excitation-contraction coupling, inefficient energy production, and increased susceptibility to ischemia. Loss of normal blood capillaries and remodeling of the extracellular matrix are also involved in diabetic cardiomyopathy $[43,44]$.

Oxidative stress has been long associated with the pathogenesis of diabetic cardiomyopathy. Prolonged hyperglycemia produces series of secondary transducers such as increase in reactive oxygen species (ROS), decreased nitrous oxide level, which leads to myocardial inflammation and endothelial dysfunction through PARP [poly (ADP-ribose) polymerase] inhibition. Anatomical and functional abnormalities of the vascular endothelium are commonly associated with diabetes [45].

\section{PATHOPHYSIOLOGICAL CHANGES INVOLVED IN CARDIOMYOPATHY}

\section{Left ventricular hypertrophy (LVH)}

The change in myocardial tissue due to diabetes is not an immediate pathogenesis but rather a consequence of long-term diabetesassociated changes, such as obesity. As per the findings of Eguchi et al. [44], there is a significant interaction between diabetes and central obesity on the risk for development of LVH. Furthermore, obesity promotes concentric LVH independently of hypertension. The recent clinical findings explain the role of cytokines, produced by the expanded adipose tissue due to obesity, in the development of LVH. For example, leptin is linked to cardiac hypertrophy in obese humans and directly induces cardiomyocyte hypertrophy in vitro. The mechanisms by which leptin induces LVH is not fully characterized but might involve endothelin 1- mediated ROS generation. The strong heart study conducted in Native Americans, found that both men and women with diabetes had higher LV mass and wall thickness. Furthermore, in a multi-ethnic population, the likelihood of having LV mass that exceeds the $75^{\text {th }}$ percentile is greater in patients with type 2 diabetes, after adjusting for various covariates including hypertension [46-49].

\section{Oxidative stress}

There are many experimental studies which have suggested that oxidative stress may play a critical role in the development of diabetic cardiomyopathy; however, the mechanism involved in ROS generation in diabetic hearts is not well understood. Clinical and pharmacological experimental studies have implicated that increased oxidative stress is associated with lipid overload; indeed, oxidative stress is increased in hearts isolated from the $\mathrm{db} / \mathrm{db}$ mice model of type 2 diabetes, which are also characterized by cardiac lipid accumulation and increased mitochondrial fatty acid oxidation. Two different experimental models were designed to study the impact of fatty acids in ROS production. One model was designed on $\mathrm{db} / \mathrm{db}$ mice, whereas the other on Akita mouse. In $\mathrm{db} / \mathrm{db}$ hearts, oxidative stress is exacerbated in the presence of fatty acids, which we believe leads to mitochondrial uncoupling. Whereas the Akita mouse model of Type 1 diabetes does not exhibit increased mitochondrial ROS generation or shows any evidence of mitochondrial uncoupling despite increased rates of fatty acid oxidation. An important distinction between the hearts of Akita mice versus $\mathrm{db} / \mathrm{db}$ or ob/ob mice is the presence of myocardial insulin resistance in obese models with insulin resistance, whereas in Type 1 diabetes models, insulin sensitivity is preserved. Interestingly, in mice with cardiac-specific deletion of insulin receptors, hydrogen peroxide production was increased, and mitochondria were uncoupled even at stage when myocardial fatty acid oxidation was reduced. This information indicates the possibility that myocardial insulin resistance may specifically 
Table 1: Criteria of trials

\begin{tabular}{|c|c|c|c|c|}
\hline \multicolumn{5}{|c|}{$\begin{array}{l}\text { Safety profile } \\
\text { Tolerability } \\
\text { Number of significant drug interactions } \\
\text { Cost }\end{array}$} \\
\hline $\begin{array}{l}\text { Line of treatment and } \\
\text { number of trials }\end{array}$ & Type of clinical trial & $\begin{array}{l}\text { Name of the } \\
\text { drug }\end{array}$ & Study of the trial & References \\
\hline $\begin{array}{l}\text { First-line treatment (three } \\
\text { or more randomized } \\
\text { clinical trials) } \\
\text { Other first line drugs }\end{array}$ & $\begin{array}{l}\text { Randomized } \\
\text { placebo-controlled } \\
\text { trials on } \\
\text { different tricyclic } \\
\text { antidepressants }\end{array}$ & $\begin{array}{l}\text { Gabapentin } \\
\text { Imipramine } \\
\text { Amitriptyline } \\
\text { Duloxetine }\end{array}$ & $\begin{array}{l}\text { This study examined the use of gabapentin extended } \\
\text { release which is not currently commercially available } \\
\text { This was a randomized control trial of venlafaxine } \\
\text { v/s imipramine in neuropathic pain and included } \\
15 \text { patients with painful diabetic neuropathy }\end{array}$ & {$[23-31]$} \\
\hline $\begin{array}{l}\text { Second line treatment (two } \\
\text { or more randomized } \\
\text { clinical trials) }\end{array}$ & $\begin{array}{l}\text { Randomized } \\
\text { placebo-controlled } \\
\text { trials on different } \\
\text { Anticonvulsant } \\
\text { drugs (Supported by } \\
\text { evidence from two } \\
\text { or more randomized } \\
\text { clinical trials in painful } \\
\text { diabetic neuropathy.) }\end{array}$ & $\begin{array}{l}\text { Venlafaxine } \\
\text { Valproate }\end{array}$ & $\begin{array}{l}\text { This study examined use of venlafaxine extended } \\
\text { release } \\
\text { This was a double-blind, randomized } \\
\text { placebo-controlled trial in diabetic neuropathy which } \\
\text { found that both valproate and a combination of } \\
\text { valproate plus glyceryl trinitrate spray improved pain } \\
\text { control }\end{array}$ & {$[32,33]$} \\
\hline $\begin{array}{l}\text { Third line treatment (two } \\
\text { or more randomized } \\
\text { clinical trials but with } \\
\text { conflicting data.) }\end{array}$ & $\begin{array}{l}\text { Supportive randomized } \\
\text { controlled trials as } \\
\text { well as conflicting } \\
\text { randomized trials }\end{array}$ & $\begin{array}{l}\text { Lamotrigine } \\
\text { Oxcarbazepine } \\
\text { Alpha lipoic } \\
\text { acid }\end{array}$ & $\begin{array}{l}\text { A randomized control trial was carried out comparing } \\
\text { lamotrigine with amitriptyline and placebo for the } \\
\text { treatment of painful diabetic neuropathy } \\
\text { Another study with conflicting results examined } \\
\text { lamotrigine dose up to } 400 \mathrm{mg} \text { /day and dosing at } \\
200 \mathrm{mg} / \text { day for neuropathic pain } \\
\text { A study examined oxcarbazepine dosing at } 600 \text {, } \\
1200 \text {, and } 1800 \mathrm{mg} / \text { day. The results were not } \\
\text { statistically significant in respect to efficacy variable, } \\
\text { but improvement in pain was observed in patients } \\
\text { receiving } 1200 \text { or } 1800 \mathrm{mg} / \text { day in comparison to } \\
\text { placebo and } 600 \mathrm{mg} / \text { day group } \\
\text { Two more studies were studies were carried out which } \\
\text { examined oxcarbazepine dosing at } 1800 \mathrm{mg} / \text { day and } \\
1200 \mathrm{mg} / \text { day the latter, however, showed conflicting } \\
\text { results } \\
\text { A randomized, placebo-controlled trial was conducted, } \\
\text { and a trial with conflicting results was also carried out }\end{array}$ & [34-41] \\
\hline
\end{tabular}

subject cardiac mitochondria to cause free radical overproduction through mechanisms that remain to be elucidated [50-52].

\section{Interstitial fibrosis}

Regan et al. stated in their study that diabetic cardiomyopathy is characterized by interstitial and perivascular fibrosis. Found a significant increase in collagen deposition around intramural vessels and between myofibers in heart biopsies form diabetic patients. In addition, a significant increase in collagen Type III but not Type I or VI was found in endomyocardial biopsies obtained from patients with Type 2 diabetes, who did not have significant coronary artery disease and hypertension. Similar to humans, some animal models with Type 2 diabetes also exhibited an increase in cardiac fibrosis even before the onset of hyperglycemia which shows increased extracellular fibrosis and collagen deposition as reported in the pre-diabetic stage in OLETF rats, a genetic model of diabetes resembles human Type 2 diabetes [53-55].

\section{CLINICAL DIAGNOSIS OF DIABETIC CARDIOMYOPATHY}

The structural and functional changes observed in the left ventricle (LV) of the heart, excluding other heart diseases being responsible for these changes in a diabetic patient, that occur as a result of prolonged diabetes, form the basis for the diagnosis of diabetic cardiomyopathy. There are certain specific biomarkers and their respective detection tools which serve as the diagnostic techniques of diabetic cardiomyopathy
(Table 2), tissue Doppler imaging (TDI) and strain/strain rate imaging (SRI) being the most common of them. LV diastolic dysfunction, easily detected by TDI at exercise stress, may be the earliest sign of diabetesinduced LV dysfunction. Thus, normal echocardiographic studies at rest are unable detect presence of diabetic cardiomyopathy. The latest studies illustrate that diastolic dysfunction develops earlier than systolic dysfunction in diabetic hearts. However, Ernande et al. [56] recently reported that systolic longitudinal strain rate was abnormal in $28 \%$ of diabetic patients with normal diastolic function and in $35 \%$ of those with diastolic dysfunction. Assessment of interstitial fibrosis by integrated backscatter or Gd-enhancement of cardiac MRI is possible, but its diagnostic value has not yet been established [57-60]. A promising novel approach to diagnosis of diabetic cardiomyopathy is analysis of metabolic changes associated with the myocardium by ${ }^{31} \mathrm{P}-\mathrm{MRS}$ and by ${ }^{1} \mathrm{H}$-MRS (magnetic resonance spectroscopy [MRS]). A parameter for detection of energy charge, the PCr/ATP ratio, is found to be reduced in the myocardium of diabetic patients when compared with that of control subjects. The newer studies using ${ }^{1} \mathrm{H}$-MRS have demonstrated that increase in myocardial triglyceride content (also known as; myocardial steatosis) was also found to be associated with $\mathrm{LV}$ diastolic dysfunction in diabetic patients. It is worthwhile to mention here that, myocardial steatosis was observed to be associated with $\mathrm{LV}$ longitudinal strain and with systolic/diastolic strain rates also, as determined by two-dimensional speckle tracking imaging in patients with uncomplicated diabetes mellitus. The possibility that myocardial 


\section{Table 2: Diagnostic clues of diabetic cardiomyopathy}

\begin{tabular}{l}
\hline Structural changes \\
LV hypertrophy assessed by 2D echocardiography or CMR \\
Increased integrated backscatter in the LV (septal and posterior \\
wall) \\
Late Gd-enhancement of the myocardium in CMR \\
Functional changes \\
LV diastolic dysfunction assessed by pulsed Doppler \\
echocardiography and TDI \\
LV systolic dysfunction demonstrated by TDI/SRI \\
Limited systolic and/or diastolic functional reserve assessed by \\
exercise TDI \\
Metabolic changes \\
Reduced cardiac PCr/ATP detected by 31P-MRS \\
Elevated myocardial triglyceride content detected by 1H-MRS \\
\hline CMR: Cardiac magnetic resonance imaging, 2D two dimensional, LV: Left \\
ventricular, MRS: Magnetic resonance spectroscopy, SRI strain/SRI: Strain/ \\
strain rate imaging, TDI: Tissue Doppler imaging [65]
\end{tabular}

steatosis is a specific marker of the diabetic cardiomyopathy warrants further investigation [61-63]. The various clinical and pathological changes observed in diabetic cardiomyopathy can be diagnosed by different sophisticated techniques as mentioned in Table 2 [64].

\section{CLINICAL STUDIES FOR PREVENTION AND TREATMENT OF DIABETIC CARDIOMYOPATHY}

Although the high prevalence of subclinical myocardial dysfunction has been reported in the early stage of Type 1 diabetes mellitus (T1DM), clinically relevant heart failure is relatively rare in this type of diabetes. In an observational study conducted by Torffvit et al.; 2005, 462 T1DM patients without a previous history of heart disease were took under observation, and it was found that only 17 patients (3.7\%) developed heart failure during 12-years follow-up period. The patients who developed heart failure in this cohort were older in age (35 \pm 9 years) and had been long-term diabetic, hypertensive, had albuminuria and retinopathy as compared to patients who did not have heart failure. In contrast, heart failure develops more commonly in patients with T2DM, as being associated with other predisposing factors, such as hypertension and leading to heart failure. Thus, glycemic control alone is not sufficient for the prevention of diabetic cardiomyopathy [65-67].

A number of clinical trials have been conducted to evaluate the impact of glycemic control on the prevention of cardiovascular events in T2DM. However, endpoints in the studies were atherosclerotic cardiovascular events and death, leaving non-ischemic heart failure not specifically determined. A recently published meta-analysis by Turnbull et al.; 2009, including a total of 27,049 subjects in the UKPDS 33 (UK Prospective Diabetes Study 33), ACCORD, ADVANCE, and VADT trials showed that mortality was not affected by intensive glycemic control, with hazard risks of 1.10 for cardiovascular death $(\mathrm{p}<0.05 ; 0.84-1.42)$ and 1.04 for all-cause death $(\mathrm{p}<0.05: 0.90-1.20)$ [68].

These elucidations appear to contradict the notion, which tight glycemic control is beneficial for prevention of diabetic cardiomyopathy. However, these results do not eliminate the possibility that intensive glycemic control commenced at an earlier stage of diabetes together with control of other risk factors can prevent heart failure in diabetic patients. This speculation is supported by a few evidence. First, clinical studies using TDI showed that glycemic control improved LV diastolic function in T2DM $[69,70]$.

Second, the Steno-2 trial showed that simultaneous control of glycemia, hypertension, and dyslipidemia significantly reduced cardiovascular events and mortality in T2DM patients. Third, a recent meta-analysis of clinical trials on hypertension indicates that diabetes increases the incidence of heart failure by more than fourfold in hypertensive patients. Whether incidence and/or outcome of heart failure differ depending on the type of hypoglycemic agent selected for hyperglycemia control remains unclear. This issue has not been addressed by a prospective randomized clinical trial. Eurich et al.; 2007 conducted observational cohort studies and retrospective analyses of registered patients, and reported that use of metformin is associated with low incidence of heart failure compared with other glycemia control regimens. Furthermore, clinical outcomes in diabetic patients with heart failure were better in groups treated with metformin as reported in a trial conducted by Aguilar et al. on metformin-treated and metformin-untreated groups of diabetic patients with heart failure and showed that mortality was lower in the metformin-treated group. In contrast with metformin, thiazolidinedione (TZD) has been shown to increase the incidence of "heart failure" in diabetes compared with sulfonylurea. Unfortunately, it is not clear whether the increase in "heart failure" by TZD is due to worsening of $\mathrm{LV}$ function or just retention of fluids [71-78].

In fact, recent studies carried out by Horio et al.; 2005 and van der Meer et al.; 2009 have suggested a favorable effect of TZD on cardiac function. Pioglitazone was used for a 6 month treatment regimen followed by which diastolic function was improved as assessed using Doppler echocardiography in hypertensive patients in proportion to the amelioration of insulin resistance. The same duration of treatment with pioglitazone was also reported to improve diastolic function and LV compliance assessed using MRI in uncomplicated T2DM patients. It is critical; however, that improvement in the function could not be proven by treatment-related myocardial metabolic change diagnosed by positron emission tomography and MRS alone. Therefore, prospective clinical trials are necessary to clarify efficacies and explain the pharmacological role of hypoglycemic drugs in the prevention of diabetic cardiomyopathy [79-80].

\section{CURRENT TREATMENT APPROACH FOR DIABETIC CARDIOMYOPATHY}

The approach for the treatment of diabetic cardiomyopathy is based on four fundamentals: Lifestyle changes, maintenance of blood glucose level, modification of risk factors for cardiovascular disease, and the treatment of heart failure. However, all the above-mentioned criteria revolve around the management of cardiomyopathy to provide symptomatic relief to the patient rather than aiming to cure the root problem. Hence, we need to research other unconventional approaches to treat this complication of diabetes. Herbal drugs offer a good thrust area for this purpose as they are free from unwanted side effects and hold the extreme unexplored potential to cure diabetes and its related complications. Thus, the latter part of this review focuses on the herbal treatment approach for diabetic cardiomyopathy which demands illustrative research to find its place in the current clinical scenario.

\section{Lifestyle modification}

Smoking cessation, healthy eating habits, reduction in body weight and aerobic exercise are the cornerstones in terms of lifestyle change. It has been shown in people with diabetes mellitus type 2 that, following reduction of their body weight and increased aerobic activity, the incidence of diabetic cardiomyopathy decreased significantly [81-83].

\section{MANAGEMENT OF HYPERGLYCAEMIA AND OTHER RISK FACTORS}

The modern therapeutic arsenal has several effective medications to treat diabetes, such as metformin, sulfonylureas, glitazones, insulin, and some modern drugs, such as GLP1 agonists and antagonists of DPP4. Although these drugs appear effective in treating diabetes in people without concomitant heart failure, in patients with heart failure there are some limitations.

The classic example is metformin, which has been previously contraindicated in heart failure because of the risk of lactic acidosis. However, in clinical practice and use, it turns out that the risk of lactic acidosis associated with metformin in people with diabetes and heart failure is not so great. In addition, metformin can upregulate cardiomyocyte autophagy, which plays an important role in the prevention of diabetic cardiomyopathy in animal models. Metformin 
has also been reported to reduce mortality rates and lower all-cause hospital admissions [84-88].

\section{Treatment of heart failure}

According to the 2013 ESC Guidelines on diabetes, pre-diabetes, and cardiovascular diseases, three neurohormonal antagonistsan angiotensin-converting enzyme inhibitor (ACE-I) or angiotensin receptor blocker (ARB), a beta-blocker, and a mineralocorticoid receptor antagonist (MRA) - are the most important pharmacological agents for the treatment of all patients with heart failure and reduced LV ejection fraction, including those with diabetes mellitus. They are usually combined with a diuretic for relieving congestion and may also be supplemented by ivabradine.

\section{ACE-I and ARB}

An ACE-I is indicated in diabetes mellitus type 2 and heart failure, since it improves symptoms and reduces mortality [89-92]. The beneficial effects of ARBs are equivalent to those of ACE-I, according to subgroup analyses of clinical trials, and therefore, an ARB can be used as an alternative in ACE intolerant patients. When ACE-I and ARBs are used in patients with diabetes mellitus, monitoring of kidney function and potassium is mandatory, since nephropathy is a frequent occurrence [93]

\section{Beta-blockers}

Beta-blockers are the standard drugs for patients with systolic heart failure [94,95]. As reported by Deedwania et al:; 2005, a subgroup analysis of the MERIT-HF trial, showed that beta-blockers reduce mortality and hospital admissions and improve symptoms, significantly in both, diabetes mellitus type 2 and non-diabetic patients. Betablockers recommended in heart failure and diabetes mellitus type 2 are metoprolol succinate in the slow release form (MERIT-HF), bisoprolol (Cardiac Insufficiency Bisoprolol Study II), and carvedilol (carvedilol prospective randomized cumulative survival and carvedilol or metoprolol European Trial) [96-99]. Adverse effects of beta-blockers in patients with diabetes mellitus type 2 and heart failure include hypoglycemia, especially with non-cardioselective regimens, and negative metabolic effects (hypoglycemia, dyslipidemia and decreased insulin sensitivity) $[100,102]$

\section{MRA}

An MRA is recommended for all patients with persisting symptoms (New York Heart Association Class II-IV) and an LV ejection fraction $=35 \%$, despite treatment with an ACE-I (or, if not tolerated, an ARB) and a beta-blocker, to reduce the risk of heart failure hospitalization and premature death (Class IA). The benefit of spironolactone and eplerenone on mortality did not differ between patients with or without diabetes mellitus type 2 and heart failure. Monitoring of kidney function and potassium is mandatory, due to the increased risk of nephropathy in patients with diabetes mellitus [64,103].

\section{Diuretics}

These drugs are useful for the relief of dyspnea and edema in heart failure with fluid retention, irrespective of the ejection fraction, although there is no evidence of a reduction in mortality or morbidity. Loop diuretics are recommended, rather than thiazides, because of their better glycemic profile [104].

\section{Ivabradine}

The SHIFT trial, involving 6558 patients with heart failure, in sinus rhythm and with heart rate $=70 \mathrm{bpm}$ (3241 on ivabradine; $30 \%$ with diabetes mellitus type 2), demonstrated that ivabradine significantly reduced cardiovascular deaths and hospital admissions for worsening heart failure. The beneficial difference was similar in a pre-specified subgroup analysis of patients with and without diabetes mellitus. Finally, the presence of diabetes mellitus is not a contraindication for cardiac resynchronization therapy and/or cardiac transplantation in patients with advanced systolic heart failure. Heart failure with preserved LV ejection fraction is a primary phenotype in diabetes, and therapy to improve the prognosis of this type of heart failure is in general still under intensive investigation [105].

\section{SELECTED HERBAL DRUGS AND NATURAL COMPOUNDS FOR DIABETIC NEUROPATHY AND CARDIOMYOPATHY}

Treatment of diabetic cardiomyopathy and neuropathy is based on the general therapeutic rules of heart failure and pain respectively; therefore, further investigation studies are required for prevention and treatment of these two complex conditions. With increased significance of the two aforesaid conditions, this review has summarized the associated structural, functional and metabolic changes to provide a novel and more targeted therapies free of side effects. With this view, some lesser known, potentially strong herbal therapies for diabetic cardiomyopathy and neuropathy are illustrated. These have huge potential to improve the quality of life of patients. As the mechanisms responsible for diabetic cardiomyopathy and neuropathy continue to be elucidated, it is hoped that these insights will provide the impetus for novel therapies that reduce the risk of heart failure and debilitating pain in individuals with diabetes mellitus and are free of the hazardous side effects which currently in use medications pose to diabetic patients [106].

Flavonoids form a class of benzo-gamma pyrone derivatives that are pharmacologically very potent. Quercetin, for instance, found most abundantly among dietary flavonols, is a potent antioxidant due to its all the right structural features for free radical scavenging activity. It is evident that the flavonoids play an important role in the various types of metabolic activities of life. They have also been suggested to play a protective role in liver diseases, cataracts, and cardiovascular diseases [107].

Curcumin is known to have shown a neuroprotective effect in multiple animal models and has great potential for the prevention or treatment of age-related neuropathy arising from chronic diabetes. Curcumin, being pharmacologically safe and effective, is a potential compound for treatment and prevention of a wide spectrum of human diseases. Curcumin has been known to have a potential role in reducing serum glucose level, sciatic neuronal proteins, neuronal protein carbonyls, nociceptive, motor coordination, nerve conduction velocity, Aldose reductase COX, PG peroxidase and $\mathrm{Na}^{+} \mathrm{K}^{+}$ATPase activity [108].

\section{Acacia arabica: (Babhul)}

It is a wild growing plant, found all over India. The plant extract has an antidiabetic effect, behaving as a secretagouge stimulating the insulin release. It induces hypoglycemia in control rats but not in alloxantreated animals. Powdered seeds of $A$. arabica when administered (2, 3 and $4 \mathrm{~g} / \mathrm{kg}$ body weight) to normal rabbits induced hypoglycemic effect by initiating release of insulin from pancreatic beta cells [109].

\section{Aegle marmelos: (Bengal Quince, Bel or Bilva)}

The aqueous extract of leaves of $A$. marmelos when administered to alloxanized rats, improved digestion and reduced blood sugar level, urea, and serum cholesterol, as compared to control. Along with exhibiting antidiabetic activity, this extract also prevented peak rise in blood sugar at $1 \mathrm{~h}$ in oral glucose tolerance test [110].

\section{Azadirachta indica: (Neem)}

A. indica, commonly known as Neem, Nimtree, and Indian Lilac is a tree of family Meliaceae. The genus Azadirachta is known to have two species of which $A$. indica is native to India. The hydroalcoholic extracts of this plant showed antihyperglycemic activity in streptozotocin-induced diabetic rats, and this effect was observed due to increase in glucose uptake and glycogen deposition in isolated rat hemidiaphragm $[109,110]$. Apart from having anti-diabetic activity, this plant has also been reported to possess antibacterial, antimalarial, antifertility, hepatoprotective, and antioxidant properties [112].

\section{Eugenia jambolana: (Indian gooseberry, jamun)}

E.jambolana is usedashouseholdremedy fordiabetesin India,specifically the decoction of its kernels. Hence, it forms a major constituent of 
many herbal formulations for diabetes. Antihyperglycemic effect of aqueous and alcoholic extract as well as lyophilized powder shows hypoglycemic activity. This varies with the different level of diabetes. As found in a study by Chattopadhyay et al., in mild diabetes (plasma sugar $>180 \mathrm{mg} / \mathrm{dl}$ ) it shows $73.51 \%$ reduction, whereas in moderate (plasma sugar $>280 \mathrm{mg} / \mathrm{dl}$ ) and severe diabetes (plasma sugar $>400 \mathrm{mg} / \mathrm{dl}$ ) it is reduced to $55.62 \%$ and $17.72 \%$, respectively. The extract of jamun pulp showed the hypoglycemic activity in streptozotocin-induced diabetic mice within 30 min of administration, whereas the seed of the same fruit required $24 \mathrm{hrs}$. The oral administration of the extract resulted in increased serum insulin level in diabetic rats. Insulin secretion was found to be stimulated on incubation of plant extract with isolated islets of Langerhans from normal as well as diabetic animals. These extracts also inhibited insulinase activity from liver and kidney [113].

\section{Tinospora cordifolia: (Guduchi)}

It is a large, glabrous, deciduous climbing shrub belonging to the family Menispermaceae. It is commonly known as Guduchi or Giloe. T. cordifolia is widely used in Indian Ayurvedic medicine for treating diabetes mellitus. Although the aqueous extract at a dose of $400 \mathrm{mg} / \mathrm{kg}$ could show a significant antihyperglycemic effect in different animal models, its effect was equivalent to only one unit $/ \mathrm{kg}$ of insulin. It is reported that the daily administration of either alcoholic or aqueous extract of T. cordifolia decreases the blood glucose level and increases glucose tolerance in rodents.

\section{CONCLUSION}

Medicinal plants are being scientifically explored once again for the treatment of diabetes. Many conventional drugs have been derived from prototypic molecules in medicinal plants. Metformin exemplifies an efficacious oral glucose-lowering agent. Its development was based on the use of Galega officinalis to treat diabetes. G. officinalis is rich in guanidine, the hypoglycemic component. Because guanidine is too toxic for clinical use, the alkyl biguanides synthalin A and synthalin B were introduced as oral anti-diabetic agents in Europe in the 1920s but were discontinued after insulin became more widely available. However, experiment with guanidine and biguanides lead to the development of metformin. Till date, over 400 traditional plant treatments for diabetes have been reported, although only a small number of these have received a scientific and medical evaluation to assess their efficacy. The World Health Organization Expert Committee on Diabetes has recommended that traditional medicinal herbs be further investigated. The major hindrance in the amalgamation of herbal medicine in modern medical practices is a lack of scientific and clinical data proving their efficacy and safety. There is a need for conducting clinical research in herbal drugs, developing simple bioassays for biological standardization, pharmacological and toxicological evaluation, and developing various animal models for toxicity and safety evaluation. It is also important to extract the active components from these plant extracts.

\section{ACKNOWLEDGMENT}

The authors are thankful to Professor S. W. Akhtar, Honourable Vice Chancellor, Integral University, for providing all the necessary facilities and resources for this work.

\section{REFERENCES}

1. Narayan KM, Gregg EW, Fagot-Campagna A, Engelgau MM, Vinicor F. Diabetes-a common, growing, serious, costly, and potentially preventable public health problem. Diabetes Res Clin Pract 2000;50:S77-84

2. Zatalia SR, Sanusi H. The role of antioxidants in the pathophysiology, complications, and management of diabetes mellitus. Acta Med Indones 2013;45:141-7.

3. Diabetes - A Global Threat. Available from: http://www.thelancet. com/journals/lancet/article/PIIS0140-6736(09)60954-5/fulltext. [Last accessed on 2014 Mar 03].

4. Patel A, Chalmers J, Poulter N. ADVANCE: Action in diabetes and vascular disease. J Hum Hypertens 2005;19 Suppl 1:S27-32.

5. WHO maps noncommunicable disease trends in all countries: Country profiles on noncommunicable disease trends in 193 countries. Cent Eur J Public Health 2011;19(3):130, 138

6. Chang CL, Lin Y, Bartolome AP, Chen YC, Chiu SC, Yang WC. Herbal therapies for Type 2 diabetes mellitus: Chemistry, biology, and potential application of selected plants and compounds. Evid Based Complement Alternat Med 2013;2013:378657.

7. Espelt A, Borrell C, Palència L, Goday A, Spadea T, Gnavi R, et al. Socioeconomic inequalities in the incidence and prevalence of Type 2 diabetes mellitus in Europe. Gac Sanit 2013;27(6):494-501.

8. Kuritzky L. Managing diabetic peripheral neuropathic pain in primary care. J Fam Pract 2010;59 5 Suppl: S15-22.

9. Ko SH, Kwon HS, Yu JM, Baik SH, Park IB, Lee JH, et al. Comparison of the efficacy and safety of tramadol/acetaminophen combination therapy and gabapentin in the treatment of painful diabetic neuropathy. Diabet Med 2010;27(9):1033-40.

10. Baruah MP, Kalra S, Ranabir S. Metformin; A character actor in the leptin story! Indian J Endocrinol Metab 2012;16 Suppl 3:S532-3.

11. Tyagi N, Goel R. Models for neuropathic pain: A review. Int J Pharm Pharm Sci 2014;6:36-9.

12. Davies M, Brophy S, Williams R, Taylor A. The prevalence, severity, and impact of painful diabetic peripheral neuropathy in Type 2 diabetes. Diabetes Care 2006;29(7):1518-22

13. Ziegler D, Ametov A, Barinov A, Dyck PJ, Gurieva I, Low PA, et al. Oral treatment with alpha-lipoic acid improves symptomatic diabetic polyneuropathy: The SYDNEY 2 trial. Diabetes Care 2006;29(11):2365-70.

14. Huizinga MM, Peltier A. Painful diabetic neuropathy: A managementcentered review. Clin Diabetes 2007;25:6-15.

15. Said G. Diabetic neuropathy-a review. Nat Clin Pract Neurol 2007;3(6):331-40.

16. Gordois A, Scuffham P, Shearer A, Oglesby A, Tobian JA. The health care costs of diabetic peripheral neuropathy in the US. Diabetes Care 2003;26(6):1790-5.

17. Gore M, Brandenburg NA, Hoffman DL, Tai KS, Stacey B. Burden of illness in painful diabetic peripheral neuropathy: The patients' perspectives. J Pain 2006;7(12):892-900.

18. Gore M, Sadosky A, Leslie D, Sheehan AH. Selecting an appropriate medication for treating neuropathic pain in patients with diabetes: A study using the U.K. and Germany Mediplus databases. Pain Pract 2008;8(4):253-62.

19. Van Acker K, Bouhassira D, De Bacquer D, Weiss S, Matthys K, Raemen $\mathrm{H}$, et al. Prevalence and impact on quality of life of peripheral neuropathy with or without neuropathic pain in Type 1 and Type 2 diabetic patients attending hospital outpatients clinics. Diabetes Metab 2009;35(3):206-13.

20. Daniell HW. Hypogonadism in men consuming sustained-action oral opioids. J Pain 2002;3(5):377-84

21. Lee C, Ludwig S, Duerksen DR. Low serum cortisol associated with opioid use: Case report and review of the literature. Endocrinologist 2002; $12: 5-8$

22. Risdahl JM, Khanna KV, Peterson PK, Molitor TW. Opiates and infection. J Neuroimmunol 1998;83(1-2):4-18.

23. Sandercock D, Cramer M, Wu J, Chiang YK, Biton V, Heritier M. Gabapentin extended release for the treatment of painful diabetic peripheral neuropathy: Efficacy and tolerability in a double-blind, randomized, controlled clinical trial. Diabetes Care 2009;32:e20.

24. Sindrup SH, Bach FW, Madsen C, Gram LF, Jensen TS. Venlafaxine versus imipramine in painful polyneuropathy: A randomized, controlled trial. Neurology 2003;60(8):1284-9.

25. Bansal D, Bhansali A, Hota D, Chakrabarti A, Dutta P. Amitriptyline versus Pregabalin in painful diabetic neuropathy: A randomized double blind clinical trial. Diabetes Med 2009;26:1019-26.

26. Morello CM, Leckband SG, Stoner CP, Moorhouse DF, Sahagian GA. Randomized double-blind study comparing the efficacy of gabapentin with amitriptyline on diabetic peripheral neuropathy pain. Arch Intern Med 1999;159(16):1931-7.

27. Max MB, Lynch SA, Muir J, Shoaf SE, Smoller B, Dubner R. Effects of desipramine, amitriptyline, and fluoxetine on pain in diabetic neuropathy. N Engl J Med 1992;326(19):1250-6.

28. Armstrong DG, Chappell AS, Le TK, Kajdasz DK, Backonja M, D'Souza DN, et al. Duloxetine for the management of diabetic peripheral neuropathic pain: Evaluation of functional outcomes. Pain Med 2007;8(5):410-8.

29. Wernicke JF, Pritchett YL, D'Souza DN, Waninger A, Tran P, Iyengar S, et al. A randomized controlled trial of duloxetine in diabetic peripheral neuropathic pain. Neurology 2006;67(8):1411-20.

30. Goldstein DJ, Lu Y, Detke MJ, Lee TC, Iyengar S. Duloxetine 
vs. placebo in patients with painful diabetic neuropathy. Pain 2005;116(1-2):109-18.

31. Raskin J, Pritchett YL, Wang F, D'Souza DN, Waninger AL, Iyengar S, et al. A double blind randomized multicenter trial comparing duloxetine with placebo in the management of diabetic peripheral neuropathic pain. Pain Med 2005;6:346-56.

32. Rowbotham MC, Goli V, Kunz NR, Lei D. Venlafaxine extended release in the treatment of painful diabetic neuropathy: A double-blind, placebo-controlled study. Pain 2004;110(3):697-706.

33. Agrawal RP, Goswami J, Jain S, Kochar DK. Management of diabetic neuropathy by sodium valproate and glyceryl trinitrate spray: A prospective double-blind randomized placebo-controlled study. Diabetes Res Clin Pract 2009;83(3):371-8.

34. Jose VM, Bhansali A, Hota D, Pandhi P. Randomized double-blind study comparing the efficacy and safety of lamotrigine and amitriptyline in painful diabetic neuropathy. Diabet Med 2007;24(4):377-83.

35. Vinik AI, Tuchman M, Safirstein B, Corder C, Kirby L, Wilk K, et al. Lamotrigine for treatment of pain associated with diabetic neuropathy: Results of two randomized, double-blind, placebo-controlled studies. Pain Med 2007;128:169-79.

36. McCleane G. $200 \mathrm{mg}$ daily of lamotrigine has no analgesic effect in neuropathic pain: A randomised, double-blind, placebo controlled trial. Pain 1999;83(1):105-7.

37. Beydoun A, Shaibani A, Hopwood M, Wan Y. Oxcarbazepine in painful diabetic neuropathy: Results of a dose-ranging study. Acta Neurol Scand 2006;113(6):395-404

38. Dogra S, Beydoun S, Mazzola J, Hopwood M, Wan Y. Oxcarbazepine in painful diabetic neuropathy: A randomized, placebo-controlled study. Eur J Pain 2005;9(5):543-54.

39. Grosskopf J, Mazzola J, Wan Y, Hopwood M. A randomized, placebocontrolled study of oxcarbazepine in painful diabetic neuropathy. Acta Neurol Scand 2006;114(3):177-80.

40. Reljanovic M, Reichel G, Rett K, Lobisch M, Schuette K, Möller W, et al. Treatment of diabetic polyneuropathy with the antioxidant thioctic acid (alpha-lipoic acid): A two year multicenter randomized doubleblind placebo-controlled trial (ALADIN II). Alpha lipoic acid in diabetic neuropathy. Free Radic Res 1999;31(3):171-9.

41. Hovaguimian A, Gibbons CH. Clinical approach to the treatment of painful diabetic neuropathy. Ther Adv Endocrinol Metab 2011;2(1):27-38

42. Trachanas K, Sideris S, Aggeli C, Poulidakis E, Gatzoulis K, Tousoulis D, et al. Diabetic cardiomyopathy: From pathophysiology to treatment. Hellenic J Cardiol 2014;55(5):411-21.

43. Rubler S, Dlugash J, Yuceoglu YZ, Kumral T, Branwood AW, Grishman A. New type of cardiomyopathy associated with diabetic glomerulosclerosis. Am J Cardiol 1972;30(6):595-602.

44. Ravindra P, Vanishree S, Sujatha S, Kishore K. Effect of carvedilol on pharmacokinetics and pharmacodynamics of glipizide. Int J Pharm Pharm Sci 2012;4(3):133-8.

45. Devereux RB, Roman MJ, Paranicas M, O’Grady MJ, Lee ET, Welty TK, et al. Impact of diabetes on cardiac structure and function: The strong heart study. Circulation 2000;101(19):2271-6.

46. Eguchi K, Boden-Albala B, Jin Z, Rundek T, Sacco RL, Homma S, et al. Association between diabetes mellitus and left ventricular hypertrophy in a multiethnic population. Am J Cardiol 2008;101(12):1787-91.

47. Woodiwiss AJ, Libhaber CD, Majane OH, Libhaber E, Maseko M, Norton GR. Obesity promotes left ventricular concentric rather than eccentric geometric remodeling and hypertrophy independent of blood pressure. Am J Hypertens 2008;21(10):1144-51

48. Barouch LA, Berkowitz DE, Harrison RW, O'Donnell CP, Hare JM. Disruption of leptin signalling contributes to cardiac hypertrophy independently of body weight in mice. Circulation 2003;108(6):754-9.

49. Xu FP, Chen MS, Wang YZ, Yi Q, Lin SB, Chen AF, et al. Leptin induces hypertrophy via endothelin-1-reactive oxygen species pathway in cultured neonatal rat cardiomyocytes. Circulation 2004;110(10):1269-75

50. Boudina S, Sena S, Theobald H, Sheng X, Wright JJ, Hu XX, et al. Mitochondrial energetics in the heart in obesity-related diabetes: Direct evidence for increased uncoupled respiration and activation of uncoupling proteins. Diabetes 2007;56(10):2457-66.

51. Bugger H, Boudina S, Hu XX, Tuinei J, Zaha VG, Theobald HA, et al. Type 1 diabetic Akita mouse hearts are insulin sensitive but manifest structurally abnormal mitochondria that remain coupled despite increased uncoupling protein 3. Diabetes 2008;57(11):2924-32.

52. Boudina S, Bugger H, Sena S, O’Neill BT, Zaha VG, Ilkun O, et al. Contribution of impaired myocardial insulin signaling to mitochondrial dysfunction and oxidative stress in the heart. Circulation
2009;119(9):1272-83.

53. Regan TJ, Lyons MM, Ahmed SS, Levinson GE, Oldewurtel HA, Ahmad MR, et al. Evidence for cardiomyopathy in familial diabetes mellitus. J Clin Invest 1977;60(4):884-99.

54. Shimizu M, Umeda K, Sugihara N, Yoshio H, Ino H, Takeda R, et al. Collagen remodelling in myocardia of patients with diabetes. J Clin Pathol 1993;46(1):32-6.

55. Mizushige K, Yao L, Noma T, Kiyomoto H, Yu Y, Hosomi N, et al. Alteration in left ventricular diastolic filling and accumulation of myocardial collagen at insulin-resistant prediabetic stage of a type II diabetic rat model. Circulation 2000;101(8):899-907.

56. Ernande L, Bergerot C, Rietzschel ER, De Buyzere ML, Thibault H, Pignonblanc PG, et al. Diastolic dysfunction in patients with Type 2 diabetes mellitus: Is it really the first marker of diabetic cardiomyopathy? J Am Soc Echocardiogr 2011;24(11):1268-75.e1

57. Picano E, Pelosi G, Marzilli M, Lattanzi F, Benassi A, Landini L, et al. In vivo quantitative ultrasonic evaluation of myocardial fibrosis in humans. Circulation 1990;81(1):58-64.

58. Pérez JE, McGill JB, Santiago JV, Schechtman KB, Waggoner AD, Miller JG, et al. Abnormal myocardial acoustic properties in diabetic patients and their correlation with the severity of disease. J Am Coll Cardiol 1992;19(1):1154-62.

59. Di Bello V, Talarico L, Picano E, Di Muro C, Landini L, Paterni M, et al. Increased echodensity of myocardial wall in the diabetic heart: An ultrasound tissue characterization study. J Am Coll Cardiol 1995;25(6):1408-15.

60. Kwong RY, Sattar H, Wu H, Vorobiof G, Gandla V, Steel K, et al. Incidence and prognostic implication of unrecognized myocardial scar characterized by cardiac magnetic resonance in diabetic patients without clinical evidence of myocardial infarction. Circulation 2008;118(10):1011-20.

61. McGavock JM, Lingvay I, Zib I, Tillery T, Salas N, Unger R, et al. Cardiac steatosis in diabetes mellitus: A $1 \mathrm{H}$-magnetic resonance spectroscopy study. Circulation 2007;116(10):1170-5.

62. Rijzewijk LJ, van der Meer RW, Smit JW, Diamant M, Bax JJ, Hammer $\mathrm{S}$, et al. Myocardial steatosis is an independent predictor of diastolic dysfunction in Type 2 diabetes mellitus. J Am Coll Cardiol 2008;52(22):1793-9.

63. Ng AC, Delgado V, Bertini M, van der Meer RW, Rijzewijk LJ, Hooi Ewe $\mathrm{S}$, et al. Myocardial steatosis and biventricular strain and strain rate imaging in patients with Type 2 diabetes mellitus. Circulation 2010;122(24):2538-44

64. Miki T, Yuda S, Kouzu H, Miura T. Diabetic cardiomyopathy: Pathophysiology and clinical features. Heart Fail Rev 2013;18(2):149-66.

65. Torffvit O, Lövestam-Adrian M, Agardh E, Agardh CD. Nephropathy, but not retinopathy, is associated with the development of heart disease in Type 1 diabetes: A 12-year observation study of 462 patients. Diabet Med 2005;22(6):723-9.

66. From AM, Leibson CL, Bursi F, Redfield MM, Weston SA, Jacobsen SJ, et al. Diabetes in heart failure: Prevalence and impact on outcome in the population. Am J Med 2006;119(7):591-9.

67. Bell DS. Heart failure: The frequent, forgotten, and often fatal complication of diabetes. Diabetes Care 2003;26(8):2433-41.

68. Turnbull FM, Abraira C, Anderson RJ, Byington RP, Chalmers JP, Duckworth WC, et al. Intensive glucose control and macrovascular outcomes in Type 2 diabetes. Diabetologia 2009;52:2288-98.

69. von Bibra H, Hansen A, Dounis V, Bystedt T, Malmberg K, Rydén L. Augmented metabolic control improves myocardial diastolic function and perfusion in patients with non-insulin dependent diabetes. Heart 2004;90(12):1483-4.

70. Hordern MD, Coombes JS, Cooney LM, Jeffriess L, Prins JB, Marwick TH. Effects of exercise intervention on myocardial function in Type 2 diabetes. Heart 2009;95(16):1343-9.

71. Gaede P, Vedel P, Larsen N, Jensen GV, Parving HH, Pedersen O. Multifactorial intervention and cardiovascular disease in patients with Type 2 diabetes. N Engl J Med 2003;348(5):383-93.

72. Andersson C, Olesen JB, Hansen PR, Weeke P, Norgaard ML, Jørgensen $\mathrm{CH}$, et al. Metformin treatment is associated with a low risk of mortality in diabetic patients with heart failure: A retrospective nationwide cohort study. Diabetologia 2010;53(12):2546-53.

73. Tang WH, Francis GS, Hoogwerf BJ, Young JB. Fluid retention after initiation of thiazolidinedione therapy in diabetic patients with established chronic heart failure. J Am Coll Cardiol 2003;41(1):1394-8.

74. Masoudi FA, Inzucchi SE, Wang Y, Havranek EP, Foody JM, Krumholz HM. Thiazolidinediones, metformin, and outcomes in older patients with diabetes and heart failure: An observational study. 
Circulation 2005;111(5):583-90.

75. Aguilar D, Bozkurt B, Pritchett A, Petersen NJ, Deswal A. The impact of thiazolidinedione use on outcomes in ambulatory patients with diabetes mellitus and heart failure. J Am Coll Cardiol 2007;50(1):32-6.

76. Erdmann E, Wilcox RG. Weighing up the cardiovascular benefits of thiazolidinedione therapy: The impact of increased risk of heart failure. Eur Heart J 2008;29(1):12-20.

77. Horio T, Suzuki M, Suzuki K, Takamisawa I, Hiuge A, Kamide K, et al. Pioglitazone improves left ventricular diastolic function in patients with essential hypertension. Am J Hypertens 2005;18(7):949-57.

78. van der Meer RW, Rijzewijk LJ, de Jong HW, Lamb HJ, Lubberink M, Romijn JA, et al. Pioglitazone improves cardiac function and alters myocardial substrate metabolism without affecting cardiac triglyceride accumulation and high-energy phosphate metabolism in patients with well-controlled Type 2 diabetes mellitus. Circulation 2009;119(15):2069-77

79. Kodama S, Tanaka S, Heianza Y, Fujihara K, Horikawa C, Shimano H, et al. Association between physical activity and risk of all-cause mortality and cardiovascular disease in patients with diabetes: A metaanalysis. Diabetes Care 2013;36:471-9.

80. Sharma AK, Srinivasan BP. Triple verses glimepiride plus metformin therapy on cardiovascular risk biomarkers and diabetic cardiomyopathy in insulin resistance type 2 diabetes mellitus rats. Eur J Pharm Sci 2009;38(5):433-44.

81. Xie Z, Lau K, Eby B, Lozano P, He C, Pennington B, et al. Improvement of cardiac functions by chronic metformin treatment is associated with enhanced cardiac autophagy in diabetic OVE26 mice. Diabetes 2011;60(6):1770-8.

82. Eurich DT, McAlister FA, Blackburn DF, Majumdar SR, Tsuyuki RT, Varney J, et al. Benefits and harms of antidiabetic agents in patients with diabetes and heart failure: Systematic review. BMJ 2007;335(7618):497

83. Aguilar D, Chan W, Bozkurt B, Ramasubbu K, Deswal A. Metformin use and mortality in ambulatory patients with diabetes and heart failure. Circ Heart Fail 2011;4(1):53-8.

84. Abesundara KJ, Matsui T, Matsumoto K. Alpha-glucosidase inhibitory activity of some Sri Lanka plant extracts, one of which, Cassia auriculata, exerts a strong antihyperglycemic effect in rats comparable to the therapeutic drug acarbose. J Agric Food Chem 2004:52:2541-5.

85. Joseph B, Jini D. An insight in hypoglycaemia effect of traditional Indian herbs used in the treatment of diabetes. Res J Med Plant 2011;5:352-76.

86. Shindler DM, Kostis JB, Yusuf S, Quinones MA, Pitt B, Stewart D, et al. Diabetes mellitus, a predictor of morbidity and mortality in the studies of left ventricular dysfunction (SOLVD) trials and registry. Am J Cardiol 1996;77(11):1017-20.

87. Rydén L, Armstrong PW, Cleland JG, Horowitz JD, Massie BM, Packer M, et al. Efficacy and safety of high-dose lisinopril in chronic heart failure patients at high cardiovascular risk, including those with diabetes mellitus. Results from the ATLAS trial. Eur Heart J 2000;21(21):1967-78.

88. Komajda M, Carson PE, Hetzel S, McKelvie R, McMurray J, Ptaszynska A, et al. Factors associated with outcome in heart failure with preserved ejection fraction: Findings from the irbesartan in heart failure with preserved ejection fraction study (I-PRESERVE). Circ Heart Fail 2011;4(1):27-35.

89. Vermes E, Ducharme A, Bourassa MG, Lessard M, White M, Tardif JC; Studies of Left Ventricular Dysfunction. Enalapril reduces the incidence of diabetes in patients with chronic heart failure: Insight from the studies of left ventricular dysfunction (SOLVD). Circulation 2003;107(9):1291-6.

90. Dickstein K, Kjekshus J; OPTIMAAL Steering Committee of the OPTIMAAL Study Group. Effects of losartan and captopril on mortality and morbidity in high-risk patients after acute myocardial infarction: The OPTIMAAL randomised trial. Optimal trial in myocardial infarction with angiotensin II antagonist losartan. Lancet 2002;360(3935):752-60

91. Haas SJ, Vos T, Gilbert RE, Krum H. Are beta-blockers as efficacious in patients with diabetes mellitus as in patients without diabetes mellitus who have chronic heart failure? A meta-analysis of large-scale clinical trials. Am Heart J 2003;146(5):848-53.

92. de Boer RA, Doehner W, van der Horst IC, Anker SD, Babalis D, Roughton $\mathrm{M}$, et al. SENIORS investigators. Influence of diabetes mellitus and hyperglycaemia on prognosis in patients $>$ or $=70$ years old with heart failure and effects of nebivolol (data from the study of effects of nebivolol intervention on outcomes and rehospitalisation in seniors with heart failure [SENIORS]). Am J Cardiol 2010;106:78-86.
93. Deedwania PC, Giles TD, Klibaner M, Ghali JK, Herlitz J, Hildebrandt P, et al. Efficacy, safety and tolerability of metoprolol $\mathrm{CR} / \mathrm{XL}$ in patients with diabetes and chronic heart failure: Experiences from MERIT-HF. Am Heart J 2005;149(41):159-67.

94. The cardiac insufficiency bisoprolol study II (CIBIS-II): A randomised trial. Lancet 1999;353(9146):9-13.

95. Packer M, Coats AJ, Fowler MB, Katus HA, Krum H, Mohacsi P, et al. Effect of carvedilol on survival in severe chronic heart failure. N Engl $\mathrm{J}$ Med 2001;344(22):1651-8

96. Hjalmarson A, Goldstein S, Fagerberg B, Wedel H, Waagstein F, Kjekshus $\mathrm{J}$, et al. Effects of controlled-release metoprolol on total mortality, hospitalizations, and well-being in patients with heart failure: The Metoprolol CR/XL Randomized Intervention Trial in congestive heart failure (MERIT-HF). MERIT-HF Study Group. JAMA 2000;283(10):1295-302.

97. Poole-Wilson PA, Swedberg K, Cleland JG, Di Lenarda A, Hanrath P, Komajda M, et al. Comparison of carvedilol and metoprolol on clinical outcomes in patients with chronic heart failure in the carvedilol or metoprolol European trial (COMET): Randomised controlled trial. Lancet 2003;362(9377):7-13.

98. Shorr RI, Ray WA, Daugherty JR, Griffin MR. Antihypertensives and the risk of serious hypoglycemia in older persons using insulin or sulfonylureas. JAMA 1997;278(1):40-3.

99. Kostis JB, Sanders M. The association of heart failure with insulin resistance and the development of Type 2 diabetes. Am J Hypertens 2005; 18:731-7.

100. Fernandez HM, Leipzig RM. Spironolactone in patients with heart failure. N Engl J Med 2000;342(2):132.

101. Swedberg K, Komajda M, Böhm M, Borer JS, Ford I, Dubost-Brama A, et al. Ivabradine and outcomes in chronic heart failure (SHIFT): Arandomised placebo-controlled study. Lancet 2010;376(9744):875-85.

102. Parabathina RK, Murlinath E, Swami LP, Krishnahari VV. Potential effect of vitamin $\mathrm{E}$, morin, rutin and quercetin against doxorubicin induced cardiomyopathy. Int J Pharm Pharm Sci 2011;3(4):280-4.

103. Nagilla B, Reddy P. Neuroprotective and anti-nociceptive effect of curcumin in diabetic neuropathy in rats. Int J Pharm Pharm Sci 2014;6(5):1331-8.

104. Dixit PP, Londhe JS, Ghaskadbi SS, Devasagayam TP. Antidiabetic and related beneficial properties of Indian medicinal plants. In: Herbal Drug Research - A Twenty First Century Perspectives. New Delhi, India: Jaypee Brothers Medical Publishers Limited; 2006. p. 377-86.

105. Wadood A, Wadood N, Shah SA. Effects of Acacia arabica and Caralluma edulis on blood glucose levels of normal and alloxan diabetic rabbits. J Pak Med Assoc 1989;39(8):208-12.

106. Chattopadhyay RR, Chattopadhyay RN, Nandy AK, Poddar G, Maitra SK. Preliminary report on anti-hyperglycaemic effect of fraction of fresh leaves of Azadiracta indica (Beng neem). Bull Calcutta Sch Trop Med 1987;35:29-33.

107. Chattopadhyay RR, Chattopadhyay RN, Nandy AK, Poddar G, Maitra SK. The effect of fresh leaves of Azadiracta indica on glucose uptake and glycogen content in the isolated rat hemi diaphragm. Bull Calcutta Sch Trop Med 1987;35:8-12.

108. Biswas K, Chattopadhyay I, Banerjee RK, Bandyopadhyay U. Biological activities and medicinal properties of neem (Azadiracta indica). Curr Sci 2002;82:1336-45.

109. Khanna P, Jain SC, Panagariya A, Dixit VP. Hypoglycaemic activity of polypeptide-p from a plant source. J Nat Prod 1981;44:648-55.

110.Stanely Mainzen Prince P, Menon VP. Hypoglycaemic and hypolipidaemic action of alcohol extract of Tinospora cordifolia roots in chemical induced diabetes in rats. Phytother Res 2003;17(4):410-3.

111. Stanely M, Prince P, Menon VP. Antioxidant action of Tinospora cordifolia root extract in alloxan diabetic rats. Phytother Res 2001;15:213-8.

112.Prince PS, Menon VP. Antioxidant activity of Tinospora cordifolia roots in experimental diabetes. J Ethnopharmacol 1999;65(3):277-81.

113. Mathew S, Kuttan G. Antioxidant activity of Tinospora cordifolia and its usefulness in the amelioration of cyclophosphamide induced toxicity. J Exp Clin Cancer Res 1997;16(4):407-11. 